\title{
BREVE ANÁLISE DE PRECONCEITO EM UMA ESCOLA ESTADUAL NA CIDADE DE MONTES CLAROS-MG
}

\section{BRIEF ANALYSIS OF PRECONCEPTION IN A STATE SCHOOL IN THE CITY OF MONTES CLAROS-MG}

Carla Milena de Moura Laurentino ${ }^{1}$ Jéssica Lorrany Sant'ana Rodrigues ${ }^{1}$ Michele Alves de Araújo ${ }^{1}$

Gildette Soares Fonseca ${ }^{2}$

\section{RESUMO}

O ser humano é movido por sentimentos que contribuem nas relações interpessoais de forma positiva e ou negativa. O preconceito, por exemplo, é o resultado da ignorância que prendem a ideias préconcebidas, podendo gerar enormes traumas, levando o sujeito até ao suicídio. No ambiente escolar, por ser reflexo da sociedade, existem diversas formas de preconceitos. Neste contexto, este artigo tem por objetivo apresentar resultados de levantamento sobre preconceito em uma escola pública da cidade de Montes Claros-MG. Para tanto, foi realizado pesquisa bibliográfica e de campo, momento que ocorreu grupo focal com aplicação de questionário. Os resultados obtidos apontam que a maioria dos pesquisados já sofreram ou realizaram algum tipo de preconceito.

Palavras-chave: Preconceito; aluno; escola; sociedade.

\section{ABSTRACT}

The human being is moved by feelings that contribute to interpersonal relationships in a positive and negative way. Prejudice, for example, is the result of ignorance that attaches to preconceived ideas, it can generate huge traumas, even suicide. In the school environment, as a reflection of society, there are several forms of prejudice. In this context, this article aims to present results of a survey on prejudice in a public school in the city of Montes Claros-Minas Gerais. To do so, he did bibliographic and field research, when a focus group occurred with the application of a questionnaire. The results obtained show that the majority of those surveyed have already suffered and or suffer some kind of prejudice.

Keywords: Preconception; student; school; society.

\footnotetext{
${ }^{1}$ Acadêmicas do curso de Geografia - Licenciatura Plena - da Universidade Estadual de Montes Claros, Unimontes. E-mail:

carlamilenaml@gmail.com, michellealara99@gmail.com,e jehlosan@yahoo.com.

${ }^{2}$ Doutora em Geografia Tratamento da Informação Espacial- Pontifícia Universidade Católica de Minas Gerais. E-mail: gildetes@yahoo.com.br
} 


\section{INTRODUÇÃO}

Os processos educativos devem ser desenvolvidos no âmbito da família, escola e sociedade. Cabe a escola, a formação educacional escolar, função que ampla e complexa, mas muitas famílias têm delegado aos profissionais da educação mais responsabilidades. Assim, são diversos aspectos que fatores que comprometem o ensino aprendizagem, dentre eles, neste estudo tratamos do preconceito.

Não é fácil reconhecer semelhanças e diferenças sociais, étnicas, econômicas, culturais no convívio escolar, e, provavelmente o mais complicado seja respeitar as diferenças, libertar crianças e jovens do preconceito, uma vez que quando adultos podem se tornar multiplicadores.

Diante do exposto, este artigo tem por objetivo apresentar resultados de levantamento sobre preconceito em uma escola pública da cidade de Montes Claros - Minas Gerais. A abordagem metodológica consistiu em pesquisa bibliográfica e de campo, onde realizamos grupo focal e aplicação de questionário. Após a compilação dos dados, podemos apontar que foi identificado expressiva quantidade de pesquisados que já sofreram/sofrem preconceito. Predomina o preconceito social, apesar de todos os estudantes estudarem na mesma escola.

\section{Considerações sobre o papel da família e da tecnologia na educação de crianças e jovens}

De acordo com o Artigo 205 da Constituição Federal de 1988, a educação é um direito de todos, além de ser dever do Estado e da família promover e incentivar que a mesma seja garantida. O Estado deve oferecer toda infraestrutura física e humana no processo educacional. A escola deverá contribuir no desenvolvimento do caráter dos estudantes, pois o seu papel é de formação educacional, é obrigação dos pais ou responsáveis acompanhar a vida escolar dos filhos. Cabe aos pais a responsabilidade de educar os filhos em valores religiosos, morais, éticos.

No Brasil, ao longo da história, há falhas graves em todo o sistema educacional por parte do Estado, da família e da escola. Além de que com a desestruturação das famílias tem ocorrido transferência de responsabilidade dos pais para os professores, o que compromete o processo de ensino aprendizagem. Especialmente, quando analisamos que a vida escolar é de suma importância na construção pessoal, profissional e social, período que construímos muitas de nossas relações, identidade, criamos vínculos, laços de amizade que podem ou não pendurar.

Conforme Gomes (1996, p. 88), o processo de construção da identidade “[...] é um dos fatores determinantes da visão de mundo, da representação de si mesmo e do outro". No 
ambiente familiar a criança inicia os primeiros contatos sociais, mas a escola que irá colaborar para a socialização. Considerando que no Brasil o ensino fundamental abrange nove anos e o ensino médio três anos, portanto, no mínimo 12 anos de escolaridade básica, além de que muitos frequentam a educação infantil de dois anos até seis anos.

De acordo com Crepaldi (2013, p. 139):

Ao entrar na escola, a criança já traz experiências que adquiriu em seu ambiente familiar, as quais a auxiliaram na formação do seu "eu" em relação ao meio. Esse processo é determinante para o seu desenvolvimento. Quando se descobre participante direta do espaço escolar, ela percebe que terá oportunidade de se relacionar com outras crianças que permanecerão com ela uma parte considerável de tempo. E que terão como educadores (as) outras pessoas adultas fora de seu convívio familiar. Se ela traz boas experiências, torna-se mais fácil continuar desse ponto.

São muitos anos que passamos no ambiente escolar, fase de mudanças hormonais, físicas e ideológicas. Outro aspecto é que na sala de aula, são muitas individualidades, realidades socioeconômicas distintas, problemas dos mais variados, especialmente nas escolas públicas, baixo aproveitamento educacional, professores doentes, sem estímulo para exercer sua função, violência, cultura do ódio, preconceito.

Nas palavras de Péres (2006, p.7), preconceito é “[...] o conceito ou opinião formados antecipadamente, sem levar em conta o fato que os conteste, intolerância, ódio racial ou aversão a outras raças, credos, religiões etc.”. Existem vários tipos de preconceitos: cultural, racial, social, linguístico, religioso, sexual, entre outros. Em relação ao preconceito sexual, o Brasil, lidera o ranking de países que mais assassina Lésbicas, Gays, Bissexuais, Travestis, Transexuais ou Transgêneros (LGBTs). Quanto, ao preconceito racial, mesmo com o fim da escravidão, permanece a discriminação aos negros e afro descentes, mesmo o Brasil sendo conhecido como uma nação de miscigenação.

O preconceito é um sentimento de elevado grau de destruição, capaz de afetar de maneira profunda, propiciar marcas no indivíduo por toda a vida, inclusive prejudicando o desenvolvimento do processo educacional, uma vez que essa prática é muito comum dentro do ambiente escolar. A escola é um espaço destinado a promover processo de aprendizado de todos, porém, há diversos empecilhos, principalmente quando se trata das relações sociais vigentes no local. $\mathrm{O}$ fato de a escola abrigar pessoas que possuem diferentes ideologia, etnia, cultura, religião, valores diversos, deveria favorecer a convivência com a diversidade, contudo o que tem ocorrido são inúmeros conflito, quase sempre por preconceito.

Em 2009, pesquisa desenvolvida pelo jornal "Gazeta do Povo", em 2009, apontou o ambiente escolar com 99,3\% de atos preconceituosos, tanto nos espaços da rede pública, como da rede privada de ensino. Por maiores que sejam os esforços para diminuir ou extinguir preconceitos nas escolas, esses ainda persistem. Problema grave, tendo em vista que o Brasil, 
além de liderar o ranking de países que mais matam LGBTs no mundo - como já mencionado - destaca o número de jovens negros assassinados como alarmante e que configura três vezes maior do que de jovens brancos.

O racismo e as práticas discriminatórias disseminadas no cotidiano brasileiro não representam simplesmente uma herança do passado. O racismo vem sendo recriado e realimentado ao longo de toda a nossa história. Seria impecável desvincular as desigualdades observadas atualmente dos quase quatro séculos de escravismo que a geração atual herdou (BRASIL, 2006, p. 18).

O filósofo grego Pitágoras já apontada que era necessário educar as crianças para evitar punir os homens, partindo desse pressuposto, é possível afirmar que as escolas,e todas as demais instituições precisam criar medidas para acabar com preconceito do cotidiano.

Além do cenário retratado, têm-se a disseminação das tecnologias de informação, que consideravelmente tem tido forte participação na formação das crianças e jovens, afetando as relações interpessoais em casa e no ambiente escolar. Apesar de facilitar o acesso a dados, informações, o que não significa que oportuniza ampliação do conhecimento e nem melhora no processo de aprendizagem. Dependendo de como as crianças e jovens fazem uso das tecnologias de informação, a situação tende a piorar, uma vez que falta limite por parte dos pais, sendo que na escola muitos estudantes não respeitam os professores, independentemente de ser pública ou privada.

Paiva, Costa (2015), consideram que o uso da tecnologia contínuo e precoce resulta em questionamentos acerca do desenvolvimento das relações afetivas e sociais da criança, visto que estas acabam substituindo as amizades reais pelas virtuais, optando em divertir no mundo virtual ao invés de jogar bola, correr e interagir com outras crianças. Devido ao rápido acesso aos mais diversificados temas, as escolas também trabalham na utilização da tecnologia para estudos e a realização de atividades, tudo que se precisa questionar, pesquisar e procurar crianças e jovens buscam na internet.

Para Paiva, Costa (2015, p.4):

A diversão e o cumprimento das atividades escolares da criança do mundo contemporâneo encontra-se basicamente dentro de casa, no computador ou tablet, nas redes sociais virtuais, onde as mesmas constituem amizades e realizam as atividades escolares por meio desses dispositivos eletrônicos sem haver a necessidade de estabelecer contato físico com a outra pessoa.

Todos esses fatos auxiliam na formação dos estudantes, mas alteram também o comportamento em sociedade com prejuízos. A internet é uma "terra" sem dono, todos podem navegar, local onde podemos encontrar muito material que nos enriqueça intelectualmente ou empobreça, além da superficialidade das relações estabelecidas nas redes sociais. As relações 
afetivas ficam mais comprometidas e cresce ódio, as intrigas, muitas fofocas, intolerância, além da vulnerabilidade na exposição da vida pessoal.

Surgem brincadeiras ofensivas, apelidos, agressões verbais que podem passar a ser físicas, muitos indivíduos são incapazes de lidar com religião do outro, o modo de vestir, as dificuldades, a orientação sexual, cultura, entre várias outras particularidades, cresce bullying e danos psicológicos. Assim como a sociedade de consumo, o ter, onde a aparência vale mais que o ser, tudo deve ser postado, desde que seja "perfeito".

Todo o turbilhão de mudanças reflete no ambiente escolar, crianças e jovens ansiosos, depressivos, perdidos, muitos optam pelo suicídio, outros estão ficando cada vez mais radicais, preconceituosos. Pais e professores, também estão perdidos diante de tantas mudanças comportamentais, valores, atitudes, enfim, a sociedade padece, tudo passou a ser superficial, banal, são os tempos líquidos. É evidente que existem, famílias estruturadas que ainda conseguem impor limites nos filhos, dão a eles educação familiar e custeiam boa educação escolar, no entanto, ficam cada vez mais raro, crianças e jovens equilibrados e felizes.

Além de que tem ocorrido perda da função primordial da escola, ou seja, oferecer educação de qualidade e preparar os estudantes para que possam conviver em sociedade de forma igualitária, pois a educação é à base do conhecimento de todo ser humano.

\section{Resultados da pesquisa}

A pesquisa foi desenvolvida com 60 estudantes do ensino médio de uma escola pública na cidade de Montes Claros-Minas Gerais. A referida escola se encontra na área central da cidade, atende público do ensino fundamental e médio. Aplicamos o questionário, além da realização de grupo focal com objetivo de identificar se há ou não preconceito no ambiente escolar.

O questionário solicitava que o estudante apontasse se já sofreu algum tipo de preconceito no ambiente escolar, dos 60 respondentes, $84 \%$ apontaram que sim, portanto $16 \%$ nunca sofreram preconceito. Também foi solicitado que apontassem o tipo de preconceito, sendo que foi dado opções (social, linguístico, racial, sexual, cultural e religioso), além de deixar a alternativa outros (Tabela 1).

Tabela 1 - Ranking dos preconceitos mais relatados pelos estudantes

\begin{tabular}{ccc}
\hline Colocação & Tipo de preconceito & $\%$ \\
\hline $1^{\circ}$ & Outros & $40 \%$ \\
$2^{\circ}$ & Social & $20 \%$ \\
\hline
\end{tabular}




\begin{tabular}{lcc}
\hline $3^{\circ}$ & Linguístico & $14 \%$ \\
$4^{\circ}$ & Racial & $12 \%$ \\
$5^{\circ}$ & Cultural & $8 \%$ \\
$6^{\circ}$ & Religioso & $3 \%$ \\
$7^{\circ}$ & Sexual & $3 \%$ \\
\hline
\end{tabular}

Fonte: Pesquisa direta, 2018. Org. ARAUJO, M. A. 2018.

É válido pontuar que devido a falta de conhecimento de alguns dos respondentes, foi necessário esclarecer cada tipo de preconceito. A maioria dos estudantes (40\%), indicou a opção outros, alguns apontaram gordofobia e homofobia.

Em relação as demais opções, obtivermos $20 \%$ para preconceito social, $14 \%$ preconceito linguístico. O preconceito racial, foi identificado em 12\%, ou seja, racismo, opinião antecipada relativa a pessoa que a diminui devido a sua etnia. Para Péres (2006. p.10): "Preconceito racial uma ofensa ao princípio da igualdade". As três categorias de preconceitos menos indicadas foram: cultural (preconceito atrelado à divergência cultural, como por exemplo, a xenofobia); religioso que está intimamente ligado à intolerância religiosa através da não aceitação das crenças alheias; sexual, que se caracteriza pelo julgamento e discriminação com uma pessoa como resultante de suas preferências sexuais.

O preconceito social, se configura ao poder aquisitivo da pessoa, ou seja, sentimento hostil que surge por um juízo pré-concebido referente às diferenças de classes sociais. A cidade de Montes Claros, por ser pólo de educação no Norte de Minas, recebe constantemente pessoas de cidades vizinhas que buscam melhores condições estudantis, porém, muitas vezes encaram a discriminação decorrente aos seus respectivos sotaques e gírias, preconceito linguístico.

No entender de Gomes (1996, p. 87):

Se concordamos que a sociedade brasileira é marcada não somente pela exploração socioeconômica, mas também pelo racismo, como desconsiderar que a escola, como uma instituição social, não seja marcada por esses fatores? E como não cobrar um posicionamento da instituição escolar diante da realidade de milhares de alunos negros no sentido não apenas de garantir-lhes o direito à Educação e proporcionarlhes um ensino de qualidade, mas de eliminar práticas discriminatórias?

Se a gestão escolar juntamente com toda a equipe não estiver envolvida para combater todos os tipos de preconceitos, a tendência é multiplicar e mais vidas serão ceifadas.

No grupo focal, identificamos características das vivências dos estudantes e encontrarmos elo entre alguns casos, a saber, a forma que o preconceito sofrido por eles, teve impacto negativo no desempenho escolar. Neste contexto, obtivemos diversos relatos, alguns retrataram como a escola se tornou ambiente desconfortável devido as constantes chacotas e 
falta de concentração. Através dos relatos, podemos pontuar que certas brincadeiras que geralmente parecem inofensivas, são capazes de atingir profundamente todo o equilíbrio e desenvolvimento de uma pessoa.

\section{Considerações finais}

Ao analisarmos brevemente o preconceito no âmbito escolar, faz necessário uma mudança dessa realidade, pensar como lidar com estas matrizes de preconceito com mais cuidado e cautela. Tendo em mente, de que não só a escola deve tornar decisões para a mudança desse quadro, pois às soluções estão além das paredes da instituição educacional. A família deve ser um dos principais, senão o principal mentor das resoluções desses problemas.

Além disso, é preciso a promoção de ações conjuntas com outras instituições, sobretudo, no âmbito da saúde e atendimento social, para atender os alunos e orientar como lidar com tais situações - agressões psicológicas, físicas, intelectuais, religiosas, sexuais etc.

\section{Referências}

BRASIL. Ministério da Educação. Secretaria da Educação Continuada, Alfabetização e Diversidade. Orientações e Ações para a Educação das Relações Étnico-Raciais. Brasília: SECAD, 2006.

CREPALDI, E. M. F. A importância da família na escola para a construção do desenvolvimento do aluno. $2013 . \quad$ Disponível em: <https://cedoc.observatoriodeeducacao.org.br/item/?cod=123456789_5116>. Acesso em: 24 outubro de 2019.

GOMES, N. L. Escola e Diversidade Étnico-Cultural: um diálogo possível. In: DAYRELL, J. (Org.) Múltiplos Olhares sobre Educação e Cultura. Belo Horizonte: Editora UFMG, 1996.

PÉRES, F. Preconceito racial uma ofensa ao princípio da igualdade. Monografia (Especialização) - Curso de Direito, Universidade do Vale do Itajaí, Itajaí, 2006. Disponível em: 〈http://siaibib01.univali.br/pdf/Fernanda\%20Peres.pdf>. Acesso em: 25 jan. 2019.

PAIVA, N. M. N. de; COSTA, J. da S. A influência da tecnologia na infância: desenvolvimento ou ameaça? Psicologia, Teresina, pp.1-13, 24 jan. 2019.

SÃO PAULO. GAZETA DO POVO. "Pesquisa comprova que preconceito atinge 99,3\% do ambiente escolar no Brasil". IN.: Gazeta do Povo. São Paulo, 17 de jun. de 2009. Disponível em: $\quad\langle$ https://www.gazetadopovo.com.br/educacao/pesquisa-comprova-que-preconceitoatinge-993-do-ambiente-escolar-no-brasil-bmg041fsqi54m7htmbm3emm32/> Acesso em: 27 de janeiro de 2019. 